\title{
Scenarios for renewable energy deployment in North African countries and electricity exchange with Europe - A model- based analysis for 2050
}

\author{
Inga Boie ${ }^{\mathrm{a}}$, Martin Pudlik ${ }^{\mathrm{a}}$, Mario Ragwitz ${ }^{\mathrm{a}}$, Frank Sensfuß ${ }^{\mathrm{a}}$, Sven Bohn ${ }^{\mathrm{b}}$, \\ Michael Agsten ${ }^{\mathrm{b}}$, Peter Bretschneider ${ }^{\mathrm{b}}$, Dirk Westermann ${ }^{\mathrm{b}}$ \\ ${ }^{a}$ Fraunhofer Institute for Systems and Innovation Research ISI/ \\ Competence Center Energy Policy and Energy Markets, Breslauer Str. 48, 76139 Karlsruhe, Germany \\ ${ }^{b}$ Fraunhofer IOSB-AST / Energy Department, Am Vogelherd 50, 98693 Ilmenau, Germany
}

\begin{abstract}
Deployment of renewable energy technologies in North Africa has large potentials for both, the coverage of the growing local electricity demand and for export of electricity to neighboring regions such as Europe. The presented research analyzes four scenarios with high shares of renewable energies in electricity generation (regional average 83-98\%) in five North African countries and evaluates the opportunities and technical challenges for exchange of electricity within the region and with Europe. It was found that extensive grid reinforcements would be required to realize the presented scenarios. With respect to inner-regional transmission capacities in North Africa, results show that, depending on the scenario, about $90 \%$ of the present grid would have to be expanded substantially in order to handle the expected transmission volumes in 2050.
\end{abstract}

Keywords: renewable energy, electricity exchange, HVDC transmission, North Africa, Europe, scenario-based modeling

\section{Introduction}

The countries of North Africa (NA) are largely characterized by a strongly rising electricity demand and energy systems which are dominated by conventional generation technologies based on fossil fuels [7]. However, the NA region also features a vast potential for the application of technologies based on renewable energy (RE) sources, such as wind energy, photovoltaic (PV) and concentrated solar power (CSP). A wider application of these technologies would, apart from obtaining a more sustainable electricity generation for covering the local demand, bear the possibility to export electricity generated by $\mathrm{RE}$ to neighboring regions such as the European Union (EU). The EU renewable energy directive for 2020 [2] already includes the possibility of importing RE for national RE-target achievement and will be developed further. Import of RE from NA was also suggested, e.g. in [3] and [4]. However, realizing such intra-regional electricity exchange, namely transmitting large volumes of electricity over long distances, is associated with a number of technical challenges related to the required grid infrastructure [14][16].

\section{Methodology}

The following section describes the scope, applied methodology and utilized models as well as the scenario setup for the analysis.

Manuscript received August 4, 2013; revised November 4, 2013.

Corresponding author: +49 721 6809-347; E-mail address: inga.boie@isi.fraunhofer.de 


\subsection{Modeling approach}

The presented research paper aims at analyzing possible scenarios for RE deployment in five North African countries, namely Algeria, Egypt, Libya, Morocco and Tunisia, and to evaluate the opportunities for inner- and intra-regional electricity exchange. In particular, the possibilities and challenges for an export of electricity to the EU and issues related to the existing transmission grid infrastructure shall be evaluated. The time horizon of the analysis covers the period until 2050.

The applied methodology combines different approaches and models. In a first step an assessment of costs and potentials for RE in NA is performed, to be able to determine cost-optimized generation portfolios for the five countries. A major input parameter for this step is an in-depth assessment of available potentials for RE technologies through analysis with a geographic information system (GIS) using the software ArcGIS (see section 3.1).

Another major determinant for the optimization of the generation portfolio is the trend in the energy demand of the analyzed countries. Therefore, a simplified, top-down model has been developed which allows for estimations of the possible future energy demand based on econometric analysis of historical data and assumptions for population growth, development of the gross domestic product (GDP), energy intensity and future trends in energy efficiency (see section 3.2).

On this basis, cost-optimized electricity generation portfolios are derived using the model PowerACE (see section 4.1). The model applies a linear optimization algorithm using a CPLEX solver to derive the cost-optimal mix of storage-, transmission-, conventional and renewable generation technologies for a given scenario setup (see section 2.2). Thereby, cost-optimized long-term scenarios (optimized in terms of minimal total system cost) are obtained which include an assessment of opportunities for the export of electricity to the EU (analogue methodology has been applied in [3]).

Part of the analysis, but not included in this paper, is also a detailed analysis on national level focusing on strategic location planning and short-term operation of individual power plants with the model RESLion and an evaluation of optimal storage design for CSP plants in NA, for exporting electricity to different EU markets [1].

Further, in order to assess the technical feasibility of the derived generation portfolios, an analysis of the existing transmission grid was done to evaluate the ability for electricity transmission and exchange and to determine required grid expansions or the need for an additional overlaying transmission grid. The modeling of the grid was done for the alternating current (AC) transmission grid in Europe and the AC transmission grid in NA based on data from [17], [18], [19], [20], [21] and [22]. The corresponding transmission grids were simulated in DIgSILENT PowerFactory. Data from [17] was used to generate Europe's AC transmission grid automatically and [18] was the basis for manually implementing the AC transmission grid in NA using the software PowerFactory. In a later step, results from the aforementioned modeling for energy transmission and exchange were used to evaluate the simulated grids and to determine required grid expansions.

\subsection{Scenario definition}

As a frame for the modeling exercises described in section 2.1, four scenarios were defined which represent possible future developments in terms of climate policy, energy efficiency and transmission grid development. Therefore, the scenarios vary in terms of $\mathrm{CO}_{2}$ emission restrictions, availability of interconnectors between NA and the EU and the level of electricity demand in both regions.

- Scenario 1 assumes moderate reductions of CO2 emissions of 50\% relative to the base year 1990 for NA and the EU. Further it is defined that the electricity demand in both regions is high and no interconnections between NA and the EU exist.

- Scenario 2 assumes more ambitious CO2 reductions of $95 \%$ in the EU and 50\% in NA (relative to 1990). A high electricity demand is defined and no interconnections between EU and NA exist.

- Scenario 3 presumes 95\% CO2 reduction for EU and 50\% for NA (relative to 1990) and a high electricity demand but allows the construction of interconnections between EU and NA.

- Scenario 4 again presumes $95 \%$ CO2 reduction for EU and 50\% for NA and allows the construction 
of interconnections between EU and NA. Additionally, a lowered electricity demand in both regions is assumed due to enhanced energy efficiency.

\section{Analysis of the Framework for Renewable Energy Deployment in North Africa}

\subsection{Wind and solar potential}

The derivation of long-term scenarios for cost-optimal electricity generation requires the detailed knowledge of the available potential for the respective RE technologies. Therefore, the first step of the analysis is a detailed assessment of areas available for deployment of each RE technology on national level. Areas which are not or only partly available due to other land use (e.g. agriculture, buildings, infrastructure, nature conservation, military purposes, etc.) or characteristics of the terrain (e.g. slope, height, soil properties, etc.) are excluded from the assessment (major data sources comprise [11] and [12]). For the remaining areas, the associated potentials for RE technologies are calculated based on data for wind speed and solar irradiation (data sources [9] and [10]). Combining the information on the available national RE potential and the expected cost of the regarded RE technologies, a cost-potential curve can be derived for each technology.

The result of this analysis for the five case study countries is summarized in Fig. 1. which shows the yearly available potential for PV, CSP and wind energy (in TWh) related to the associated marginal generation cost in $€ / \mathrm{MWh}$ (cumulated for all five countries). Fig. 2. displays a detail of the same costpotential curve for the range up to $10,000 \mathrm{TWh}$. Underlying assumptions regarding future cost and technology parameters for RE- and conventional technologies are presented in Table 3. The results show that the technically realizable potential for renewable electricity in NA exceeds the expected local electricity demand (cf. section 3.2) by far and would thus allow for considerable exports of electricity to neighboring countries and regions such as the EU. Remarkable is especially the extensive low-cost potential for wind onshore energy. In 2050, the five North African countries could, for example, generate up to $2000 \mathrm{TWh}$ wind energy per year with marginal generation costs below 50€/MWh. Nearly the same applies to PV. Potentials for electricity generation by CSP are also substantial, although generation cost are higher due to the higher investment cost for the CSP technology (cf. Table 3. Higher generation costs for CSP will (partially) be compensated by the higher system value of this technology due to its dispatchability and demand oriented supply (due to the included thermal storage).

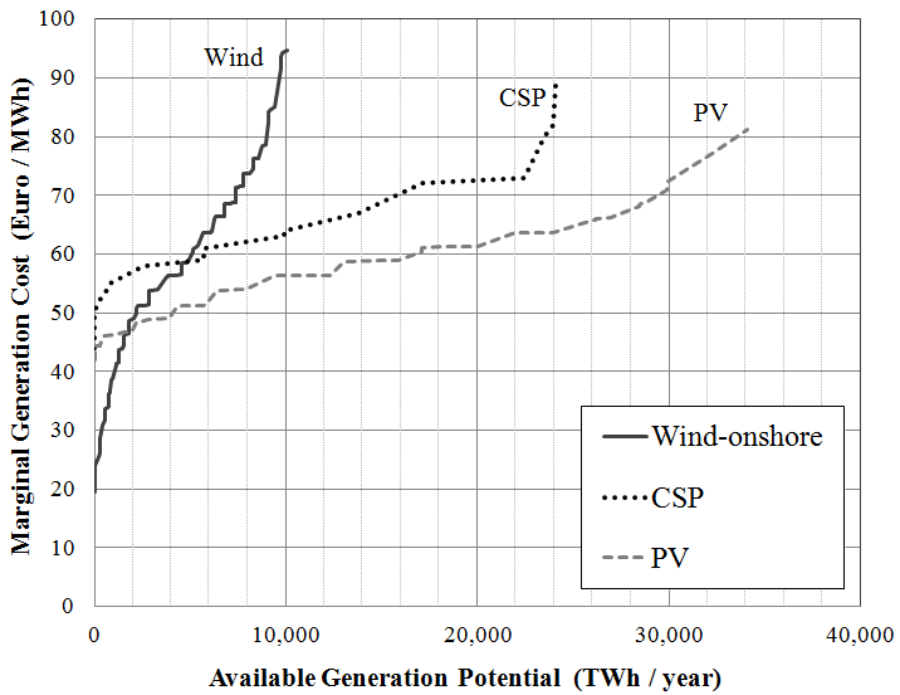

Fig. 1. Cost potential curve for PV, CSP and wind energy showing aggregated potentials for Algeria, Egypt, Libya, Morocco and Tunisia in 2050 


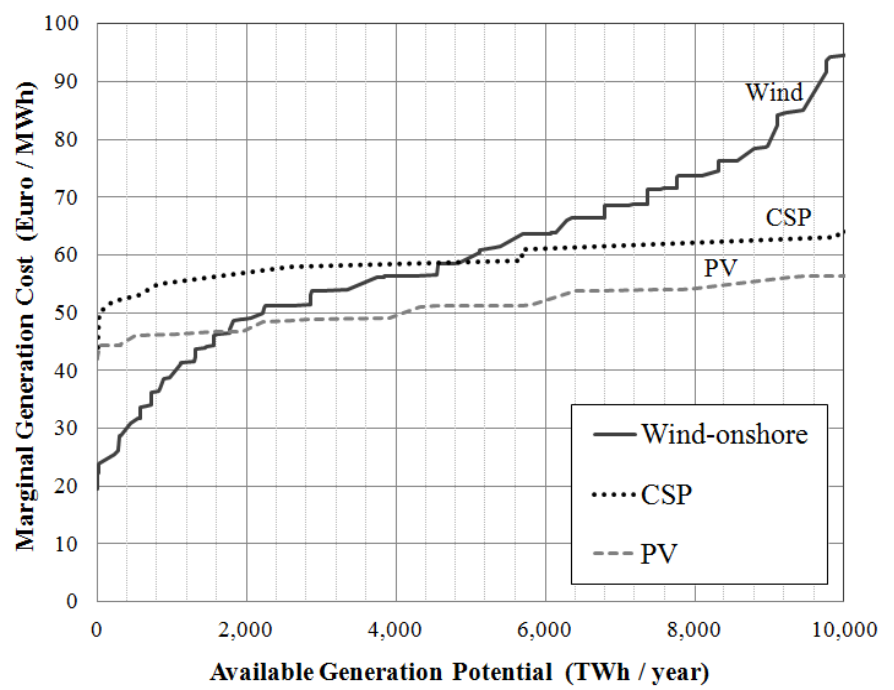

Fig. 2. Detailed cost potential curve (range $<10,000 \mathrm{TWh}$ ) for PV, CSP and wind energy showing aggregated potentials for Algeria, Egypt, Libya, Morocco and Tunisia in 2050

\subsection{Possible trends in electricity demand}

Most countries of NA show a strongly rising electricity demand, with growth rates partly exceeding $10 \%$ per year [6][7]. However, as detailed sectoral demand data is largely missing for NA, reliable longterm forecasts on the future electricity demand are mostly not available. Therefore, for the present research an approach was chosen which is based on a top-down assessment of the possible development based on econometric analysis of historical demand data (data source [6]), estimations of population growth (data source [5], medium growth scenario) and GDP development (data source [8]) under consideration of income elasticities. Thereby, two variants were regarded: A 'business as usual' case in which the growth of the demand is supposed to continue at a stable rate and an 'energy efficiency' case which assumes an overall improvement of energy efficiency of $17 \%$ until 2050.

Fig. 3 shows the resulting possible development of electricity demand in the five NA countries until 2050. Presented is the result for the case 'business as usual' which leads to a cumulated demand for all five countries of $1070 \mathrm{TWh} / \mathrm{a}$ in 2050 . The sensitivity 'energy efficiency' results in a cumulated demand of $871 \mathrm{TWh} / \mathrm{a}$ in 2050.

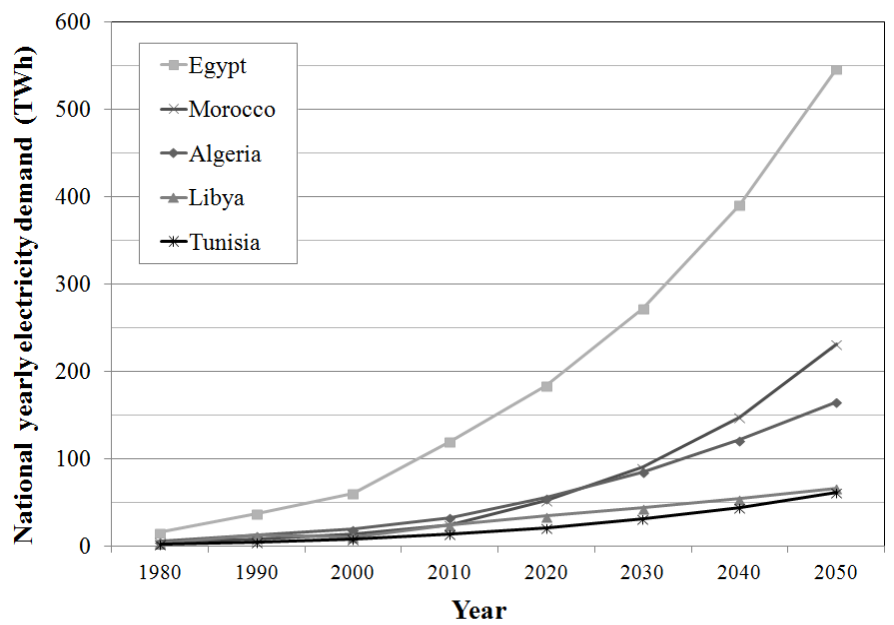

Fig. 3. Possible development of electricity demand in Algeria, Egypt, Libya, Morocco and Tunisia until 2050 (case 'business as usual') 


\subsection{Transmission grid capacities}

The present AC transmission grid consists of several separate AC transmission grids, synchronous zones and interconnections as there is no common transmission grid covering the EU and NA. Within the present research, both the current AC grid capacities and interconnections between the separated grids are evaluated. Limitations mainly apply to the interconnections. The analysis considers currently existing and planned interconnections until 2020. Thereby, at least three synchronous zones have to be considered: The Union for the Co-ordination of Transmission of Electricity synchronous zone (UCTE), the South Eastern Mediterranean Block (SEMB) and the South Western Mediterranean Block (SWMB) [22]. Data [19], [20] and [21] showed that, based on the capacities of the current and planned interconnectors, a maximum transfer limitation of $6.4 \mathrm{GW}$ between the EU and NA and $6.2 \mathrm{GW}$ among the countries within NA applies. Comparing these results with the possible development of energy exchange between EU and NA, and among the countries within NA (cf. section 4.2) shows that the current grid capacities are not sufficient for large scale energy transmission in the future and grid expansion needs to be applied.

\section{Modeling Results}

The following section provides an overview over part of the modeling results namely the resulting technology portfolios, possible electricity exchanges and implications for the transmission grids in the four scenarios. Results are presented on regional level (aggregated for the five countries) for the year 2050 .

\subsection{Cost-optimized renewable energy portfolios in 2030 and 2050}

The cost-optimized technology portfolios (annual generation volumes per technology) for the four scenarios are presented in Table 1 . The table shows the yearly generation in 2050 cumulated for all five countries. All scenarios feature high RE shares in generation of $82 \%$ (scenario 1) up to $98 \%$ (scenario 3). The results show that the regional RE potential would be sufficient to cover a large share of the local demand with only small needs for conventional balancing capacities.

Comparison of the scenario results shows that generally conventional generation technologies are replaced by $\mathrm{RE}$ technologies if more rigorous $\mathrm{CO}_{2}$ restrictions are assumed (scenarios 3 and 4). Only scenario 1 , which is characterized by a low ambition level regarding $\mathrm{CO}_{2}$ emission reductions, contains relevant amounts of coal in the generation mix as well as substantial contributions by CCGT. Wind is in all four scenarios the dominant RE technology, followed by CSP and PV. The dominance of wind energy is due to the high potential at very low costs in the region (cf. section 3.1). Electricity generation by CSP is most significant in scenarios with ambitious $\mathrm{CO}_{2}$ reduction goals in combination with a high electricity demand, as in these scenarios carbon-free, dispatchable generation and storage technologies are of high value. Generation by gas turbines (GT and CCGT) will be used for balancing purposes up to the respective $\mathrm{CO}_{2}$ emission limit applying in each scenario.

Table 1. Possible electricity generation portfolios in 2050

\begin{tabular}{lllll}
\hline & \multicolumn{5}{c}{ Generation per technology [TWh/a] } \\
\hline Wind & Scenario1 & Scenario 2 & Scenario 3 & Scenario 4 \\
\hline PV & 618 & 737 & 965 & 735 \\
CSP & 97 & 86 & 118 & 94 \\
Gas -GT & 199 & 303 & 416 & 222 \\
Gas-CCGT & 8 & 3 & 3 & 4 \\
Coal & 125 & 68 & 21 & 38 \\
Hydro & 47 & 0 & 1 & 3 \\
Total & 50 & 50 & 50 & 50 \\
RE-share & $\mathbf{1 1 4 3}$ & $\mathbf{1 2 4 7}$ & $\mathbf{1 5 7 5}$ & $\mathbf{1 1 4 6}$ \\
\hline
\end{tabular}




\subsection{Opportunities for electricity exchange}

The optimization revealed the potential energy exchange among the countries of NA and between NA and the EU in the year 2050. The summary of the results is shown in Table 2. Electricity exchanges among NA countries increase with the utilization of RE, as the energy systems change from nationally-oriented, fossil-fuel based generation, to RE-based generation, where balancing among the countries gains importance (i.p. with respect to fluctuating RE from wind and PV). In scenarios 3 and 4, in which electricity trade with the EU is possible, also the inner-regional power flows rise, as electricity must be transported from locations of generation to the respective nearest interconnectors. In scenario 4, the lower energy demand across EU and NA results in smaller electricity exchanges within and in-between the regions and thus implies fewer needs for additional transmission capacities. This result emphasizes the need for enhanced measures regarding energy efficiency in order to minimize the cost for grid upgrades.

Table 2. Electricity exchanges in 2050 per scenario

\begin{tabular}{|c|c|c|c|}
\hline & \multicolumn{3}{|c|}{ Net electricity exchanges [TWh] } \\
\hline & Within NA & NA - EU & Total \\
\hline Scenario 1 & 28 & Per definition not possible & 28 \\
\hline Scenario 2 & 37 & Per definition not possible & 37 \\
\hline Scenario 3 & 117 & 347 & 465 \\
\hline Scenario 4 & 68 & 191 & 259 \\
\hline
\end{tabular}

\subsection{Implications for transmission grids}

One result of the simulation of the AC transmission grid for the EU and NA is that the currently existing AC transmission grid will not be able to handle the expected volumes of energy in 2050 . This is a typical observation when simulating a current grid [17][18] and applying expected future volumes of energy. Therefore, the major question is how to expand the grid in order to handle the expected volumes and, at the same time, meet the requirements for stability and reliability of the transmission infrastructure (e.g. N-1 contingencies)?

There are basically two approaches for this. One of them is grid expansion. Grid expansion means that the currently existing grid will be expanded by additional lines or cables, additional transformers, rising voltage levels and installing additional compensation for reactive power.

The second way is designing an overlaying transmission grid. Especially in the context of the present research, this solution appears most suitable. Reason for this is the need for wide-area energy transmission. Wide-area energy transmission is usually done by high voltage transmission grids because of several advantages, e.g. a smaller current and therefore less thermal stress to the wires. However, high voltage transmission hast to be subdivided into two technologies. One of them is the high voltage alternating current (HVAC) transmission and the other the high voltage direct current (HVDC) transmission. When it comes to wide-area energy transmission the HVDC technology has several advantages compared to the HVAC transmission. To mention, the better interconnectivity of multiple terminals due to no need for synchronization, the absence of reactive power and therefore less losses and no need for compensation. Also based on own results [14] and literature [16][13] it is concluded that only a multi-terminal (MT) transmission grid can fulfill the requirements related to a pan-EU-NA energy exchange as individual interconnections are not leading to the same results.

As a result of these considerations it is figured that an MT-HVDC is needed to connect the European AC transmission grid with the NA transmission grid and to collect or distribute electricity over the two regions. Therefore, in a first step, the HVDC grid based on [16] was modeled and, in a second step, extended by the results of own research. The final HVDC grid will span an overlay grid across the EU (as proposed in [16]); it will comprise at least eight interconnections between Europe and NA and it will form a kind of collector grid in NA. Even installing a MT-HVDC overlay grid does not avoid grid expansion of the AC transmission grids. For NA a grid expansion of the AC transmission is determined within the simulation. It was found that approximately $90 \%$ of the wires and cables have to be expanded on average by eighteen times their current capacity in order to handle the expected transmission volumes in 2050 . 


\section{Conclusions and Outlook}

The present analysis points out that a decarbonisation of the EU and NA electricity systems based on $\mathrm{RE}$ represents an economically viable option. The NA countries possess extensive low-cost potentials for RE deployment which exceed their expected future energy demand by far and which allow exporting surplus generation to Europe. In 2050, wind energy will dominate a cost optimal solution, supplemented by PV and CSP. In case of high emission reductions, CSP technologies will be needed to balance the power system, whereas higher contributions of natural gas emerge in case of lower emission reductions.

However implementation of these scenarios implies substantial challenges for the electricity transmission infrastructure. Results of the grid simulation show that the current AC transmission grid will not be able to handle the expected volumes of electricity in 2050. Expanding the AC transmission grid will not lead to the required results because of the wide-area electricity transmission. Only a MT-HVDC grid will provide the required characteristics for a pan-EU-NA electricity exchange. Further, this MTHVDC grid needs to form a collector grid among the countries of NA to provide local energy exchange.

As such a MT-HVDC grid does not exist nowadays, further research and development is needed in before such a pan-European-NA energy exchange can be realized. Ongoing research, besides others, investigates and develops methodologies for grid operation of such MT-HVDC grids [14][15] and continues to improve the VSC technology as it is the most promising technology for MT-HVDC grids.

Moreover, ongoing research focuses on the required framework conditions for the presented transformation of the NA energy systems, regarding suitable regulatory and economic conditions for large-scale RE deployment.

\section{Acknowledgment}

This work was supported by the Fraunhofer Internal Program »Markets of Tomorrow « under Grant No. 823813 Project »Supergrid «.

\section{References}

[1] C. Kost, C. Flath, D. Möst, T. Fluri, CSP storage design and market value in an ex-port case from Morocco to Europe. presented at Solar PACES 2012. Marrakech, Morocco.

[2] European Commission, Directive 2009/28/EC of the European Parliament and of the Council of 23 April 2009 on the promotion of the use of energy from renewable sources, [Online], Available: http://eurlex.europa.eu/LexUriServ/LexUriServ.do?uri=Oj:L:2009:140:0016:0062:en:PDF

[3] F. Zickfeld et al., Desert Power 2050 - Perspectives on a sustainable power system for EUMENA, Dii GmbH, Munich, June 2012.

[4] The Club of Rome, Clean power from desert - the desertec concept for energy, water and climate security, White book, $4^{\text {th }}$ edition, 2008.

[5] UN Population Division, Data on population development, [Online], Available : http://www.un.org/esa/population/ (accessed : 05.05.2012)

[6] US Energy Information Administration, Electricity Detailed Data Files. [Online], Available: http://www.eia.gov/cneaf/electricity/page/data.html

[7] AUPTDE - Arab Union for Production, Transmission and Distribution of Electricity, "Statistical Bulletins", [Online]. Available: http://www.auptde.org/Default.aspx?lang=en

[8] The World Bank, Database on global GDP development. [Online]. Available: http://data.worldbank.org/indicator/NY.GDP.MKTP.CD

[9] NASA, Global Wind Speed Data, [Online], Available: http://gmao.gsfc.nasa.gov/merra/

[10] Helioclim, Data on Global Horizontal Irradiation (GHI) and Direct Normal Irradiation (DNI), [Online]. Available: http://www.helioclim.org/

[11] NASA, Land use Data, [Online], Available: http://modis.gsfc.nasa.gov/

[12] CGIAR, Global Digital Terrain Data, [Online], Available: http://srtm.csi.cgiar.org/

[13] DESERTEC Foundation. main webpage. [Online]. Available: www.desertec.org.

[14] W. Platzer, Supergrid: efficient generation, storage and distribution of electricity, 2011.

[15] A.-K. Marten, Integration der Betriebsführung eines HGÜ-Overlay-Netzes in die Leitungs-Frequenz-Regelung eines Drehstrom-Verbundnetzes, Ilmenau: Universitätsverlag Ilmenau, 2012.

[16] CIGRÉ WG B4-52, HVDC Grid Feasibility Study, CIGRÉ, 2012.

[17] Q. Zhou und J. W. Bialek, Approximate model of european interconnected system as a benchmark system to study effects of cross-border trades. IEEE Transactions on Power Systems, Bd. no. 2, vol. 20, pp. 782 - 789, May 2005.

[18] Arab Union of Producers, Transporters \& Distributors of Electricity, Electrical Network of Arab Countries. (2007). [Online] Available: http://www.medemip.eu/Calc/FM/MED-EMIP/AUPTDE/Electicity_Interconnection_Maps/Arab_World.pdf. 
[19] M. Hafner, Mediterranean Energy Markets and the Mediterranean Electricity Ring: Status and Perspectives for a Clean Power Market, Amman, 2005.

[20] F. Trieb, Trans-Mediterranean Interconnection for Concentrating Solar Power, Stuttgart, June 2006.

[21] The European Neighbourhood and Partnership Instrument (ENPI), Power Systems at 2020: State of play of the existing infrastructures, 2012.

[22] ENTSO-E, The Ten-Year Network Development Plan. (2012). [Online], Available: https://www.entsoe.eu/fileadmin/user_upload/_library/SDC/TYNDP/2012/TYNDP_2012_report.pdf

\section{Appendix a Modeling Assumptions}

Table 3 below gives an overview over the assumptions for technology cost and fuel prices assumed for 2050 .

Table 3. Cost and technology assumptions for renewable- and conventional technologies in 2050

\begin{tabular}{llllll}
\hline Technology & $\begin{array}{l}\text { Specific investment } \\
{[€ / \mathrm{kW}]}\end{array}$ & $\begin{array}{l}\text { O\&M cost } \\
{[€ / \mathrm{kW} / \mathrm{a}]}\end{array}$ & $\begin{array}{l}\text { Fuel cost } \\
{[€ / \mathrm{MWh}]}\end{array}$ & $\begin{array}{l}\text { Lifetime } \\
{[\text { years] }}\end{array}$ & Efficiency \\
\hline Wind & 900 & 30 & 0 & 25 & - \\
PV & 700 & 19 & 0 & 25 & - \\
CSP & 2660 & 45 & 0 & 30 & - \\
Gas-GT & 380 & 12.4 & 26.82 & 30 & 0.4 \\
Gas-CCGT & 750 & 13.8 & 26.82 & 30 & 0.6 \\
Coal & 1450 & 36 & 6.86 & 40 & 0.48 \\
Lignite & 1500 & 46.5 & 3.75 & 40 & 0.47 \\
Pump storage & 1700 & 28.9 & 0 & 40 & 0.91 \\
\hline
\end{tabular}

\section{Authors Information}

\begin{tabular}{|c|c|c|c|c|}
\hline Author name & Title & Membership & Contact & Author affiliation \\
\hline Inga Boie & S.E. & & inga.boie@isi.fraunhofer.de & \multirow{4}{*}{$\begin{array}{l}\text { Fraunhofer Institute for Systems } \\
\text { and Innovation Research ISI/ } \\
\text { Competence Center Energy Policy } \\
\text { and Energy Markets, Breslauer } \\
\text { Str. 48, } 76139 \text { Karlsruhe, } \\
\text { Germany }\end{array}$} \\
\hline Martin Pudlik & Dr. & & martin.pudlik@isi.fraunhofer.de & \\
\hline Mario Ragwitz & Dr. & & mario.ragwitz@isi.fraunhofer.de & \\
\hline Frank Sensfuß & Dr. & & frank.sensfuß@isi.fraunhofer.de & \\
\hline Sven Bohn & S.E. & & $\begin{array}{l}\text { sven.bohn@iosb- } \\
\text { ast.fraunhofer.de }\end{array}$ & \multirow{4}{*}{$\begin{array}{l}\text { Fraunhofer Institute for Advanced } \\
\text { System Technologies IOSB-AST / } \\
\text { Energy Department, Am } \\
\text { Vogelherd 50, } 98693 \text { Ilmenau, } \\
\text { Germany }\end{array}$} \\
\hline Michael Agsten & Dr. & & $\begin{array}{l}\text { michael.agsten@iosb- } \\
\text { ast.fraunhofer.de }\end{array}$ & \\
\hline $\begin{array}{l}\text { Peter } \\
\text { Bretschneider }\end{array}$ & Dr. & & $\begin{array}{l}\text { peter.bretschneider@iosb- } \\
\text { ast.fraunhofer.de }\end{array}$ & \\
\hline Dirk Westermann & Prof. & & $\begin{array}{l}\text { dirk.westermann@iosb- } \\
\text { ast.fraunhofer.de }\end{array}$ & \\
\hline
\end{tabular}

*S.E.-Senior Engineer; ** Member of IEEE-Fellow/Senior member/Member 